03

\title{
Характеристики аэрозольного облака, образующегося при микровзрывном разрушении двухжидкостной капли
}

\author{
(С) Д.В. Антонов, Г.В. Кузнецов, П.А. Стрижак \\ Национальный исследовательский Томский политехнический университет, Томск, Россия \\ ๑ E-mail: pavelspa@tpu.ru
}

Поступило в Редакцию 30 апреля 2019г.

В окончательной редакции 30 апреля 2019г.

Принято к публикации 8 мая 2019г.

\begin{abstract}
Представлены результаты экспериментальных исследований процессов микровзрывной фрагментации двухжидкостных (вода и рапсовое масло) капель при нагреве в потоке воздуха с температурой от 250 до $450^{\circ} \mathrm{C}$. В результате высокоскоростной видеорегистрации определены размеры, площадь внешней поверхности формирующегося аэрозольного облака, а также площадь свободной поверхности жидкости и выполнено их сравнение с аналогичными параметрами исходной капли. Установлены зависимости этих параметров от температуры нагрева и относительной концентрации (10-90 vol.\%) горючего компонента в составе капли. Выделены условия получения асимптотического характера данных зависимостей.
\end{abstract}

Ключевые слова: двухжидкостная капля, вода, рапсовое масло, микровзрывное разрушение.

DOI: 10.21883/PJTF.2019.16.48148.17864

Условия и характеристики процессов микровзрывной фрагментации капель и частиц с различным компонентным составом и в разном агрегатном состоянии (жидкое, твердое, гелеобразное) при интенсивном нагреве особенно активно изучаются на протяжении последних 15-20 лет [1-3]. За счет такого кратковременного (как правило, от нескольких десятков микросекунд до сотен миллисекунд [4]) дополнительного (нередко называемого „вторичным“ $[4,5])$ измельчения капель и частиц можно ускорять процессы зажигания и повышать полноту выгорания топлив, снижать антропогенные выбросы, увеличивать полноту испарения жидкостей при их термической и огневой очистке от примесей, а также в теплообменных аппаратах и при тушении пожаров. Объекты исследований в области микровзрывной фрагментации различны, но во всех составах ключевую роль играет вода как низкокипящий (относительно горючих жидкостей) компонент [5]. Последнее может способствовать растрескиванию твердых частиц, вспучиванию желейных и гелеобразных структур, наполнению капель пузырями и их схлопыванию в процессе нагрева [4-6]. При этом могут быть реализованы разные механизмы подвода теплоты к капле [5,6]: конвективный, кондуктивный, радиационный. При выполнении математического моделирования [1-3] и в экспериментах [4-6] показано, что необходимым и достаточным условием диспергирования неоднородных капелек и частиц является вскипание воды в микрообъемах (т.е. локальное), приводящее к зарождению группы пузырьков, их объединению и существенному увеличению общего пузыря в размерах. Последнее и приводит к разрушению внешней жидкостной оболочки и всей капли в целом. За счет применения оптического метода „Planar Laser Induced Fluorescence“ показано [5,6], что довольно часто перед микровзрывом температура воды в составе неоднородных капель достигает $80-100^{\circ} \mathrm{C}$. Другой часто применяемый при моделировании $[7,8]$ критерий микровзрыва состоит в достижении критического значения отношения размера образующегося при кипении пузыря к начальному размеру исходной капли. Традиционно для этого соотношения принимается диапазон от 2 до 4 [7,8]. В одной из последних публикаций по данной тематике [8] показано, что для оценки необходимых температур и длительностей нагрева капель с обеспечением условий микровзрыва достаточно применения математической модели, основанной на анализе нестационарного температурного поля капли до момента достижения температурой воды значений, близких кипению. Но ни в этой модели, ни в более полных (например, [1-3]) пока не разработаны алгоритмы адекватного прогнозирования количества и размеров новообразованных капелек (их часто называют „child-droplets“ [4]). При этом для интенсификации цепных механизмов микровзрывов совокупности капель важно знать размеры, объем и площадь внешней поверхности образующегося аэрозольного облака при микровзрыве каждой из исходных капелек. В большинстве моделей (например, [1-3]) средний размер новообразованных капелек задается как эмпирическая константа. На основе результатов опытов $[9,10]$ с каплями воды, содержащими твердые частицы, можно сделать вывод о том, что с ростом температуры нагрева и концентрации горючего компонента в составе капли эти константы могут существенно меняться. При этом важно установить максимальные возможные размеры аэрозольных облаков, получаемые при микровзрывах. В настоящей работе приведены результаты опытов, выполненных с целью регистрации этих характеристик как функций температуры нагрева и концентрации горючего компонента в составе капли.

С помощью высокоскоростной видеокамеры выполнялась регистрация процессов прогрева и измельчения 


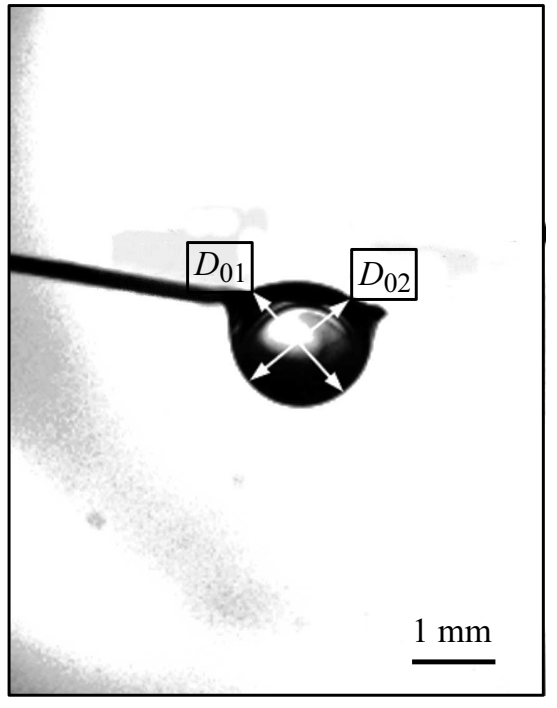

$t=0.5 \mathrm{~s}$

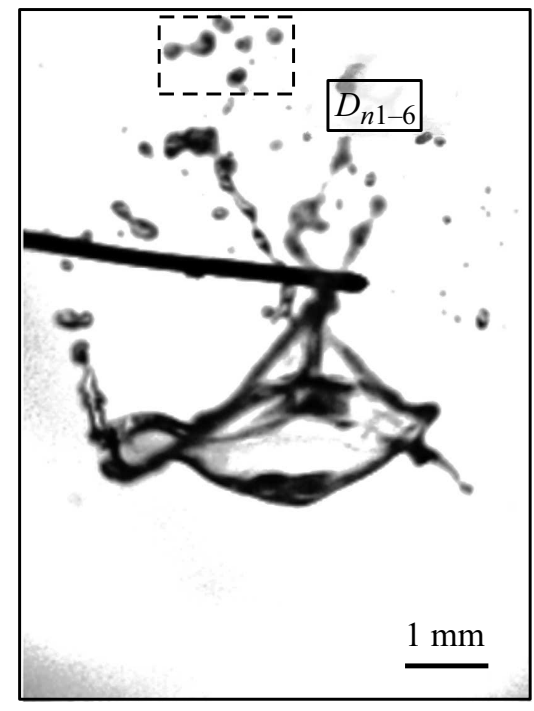

$t=0.671 \mathrm{~s}$

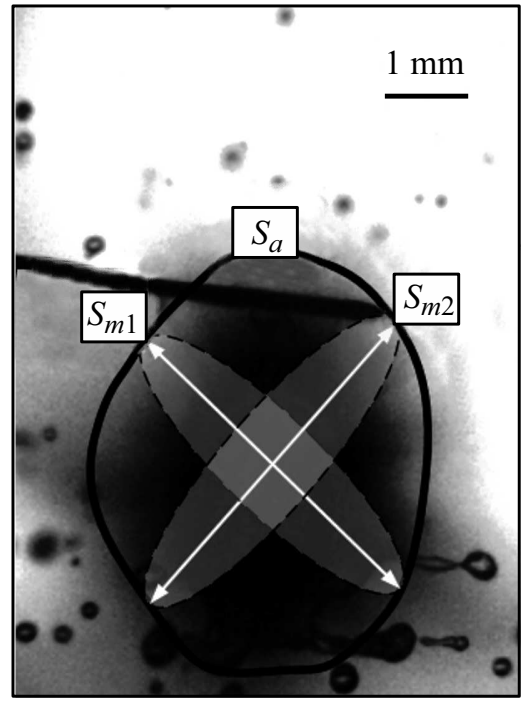

$t=0.675 \mathrm{~s}$

Рис. 1. Кадры микровзрывного распада капель (относительные объемные доли компонентов: $10 \%$ вода, 90\% рапсовое масло; диаметр $D_{0} \approx 1.5 \mathrm{~mm}$; температура нагрева $\left.T_{a} \approx 450^{\circ} \mathrm{C}\right)$ с регистрацией характерных размеров образующегося аэрозольного облака и вторичных жидкостных фрагментов.

двухкомпонентных капель при конвективном нагреве (обдувании потоком воздуха). Схема экспериментального стенда аналогична используемой в опытах [5]. Конвективный нагрев осуществлялся при применении нагревателя (Leister LHS 61, максимальная температура воздуха на выходе $700^{\circ} \mathrm{C}$ ) и нагнетателя (Leister Robust, расход воздуха до $12001 / \mathrm{min}$ ) [5]. Диапазон исследуемых температур составил $250-450^{\circ} \mathrm{C}$, скорость движения натекающего на каплю газового потока около $3 \mathrm{~m} / \mathrm{s}$. При этих температурах и скоростях движения потока капля не срывалась с держателя и устойчиво реализовались процессы взрывной фрагментации. В настоящей работе, как и в [5], более высокие температуры не изучались, так как процессы взрывного дробления двухжидкостных капель реализовались за время существенно меньше $0.5 \mathrm{~s}$. Если учесть, что капля вводится передвижным автоматизированным механизмом в рабочую область канала за $0.5 \mathrm{~s}$, то при высоких температурах сложно успеть обеспечить даже ввод исследуемого объекта в зону высокоскоростной видеорегистрации.

В экспериментах использовались наиболее перспективные по своим свойствам для экологически чистых топливных технологий составы (близки к биотопливам по антропогенным выбросам [4-6]) на основе двух компонентов: вода и рапсовое масло. В последние годы интерес к рапсовому маслу возрастает по причине его использования как биотоплива [4-6]. В проведенных экспериментах создание двухжидкостной капли подразумевало последовательную генерацию воды и масла с помещением на держатель из нихромовой проволоки с внешним диаметром около $0.2 \mathrm{~mm}$. Аналогично методике [5] использовались два электронных дозатора Finnpipette Novus (шаг варьирования генерируемого объема $0.05 \mu 1$ ). В данной схеме горючая примесь концентрировалась в нижней части, обволакивая каплю воды и создавая на ее поверхности пленку толщиной $0.05-0.5 \mathrm{~mm}$. При такой схеме регистрировалось максимальное количество вторичных капель, как и в опытах [5].

На рис. 1 представлены типичные кадры микровзрывного распада капель с регистрацией размеров образующегося аэрозольного облака. Видеозаписи взрывного разрушения капель анализировались с использованием программного обеспечения Tеma Automotive и Phantom Camera Control. Обработка видеозаписей осуществлялась в два этапа. На первом с использованием программных алгоритмов слежения Airbag и Advanced Airbag, реализованных в комплексе Tema Automotive, проводился контроль изменения формы аэрозольного облака после распада капель (рис. 1). Определялись значения площади миделевого сечения аэрозольного облака и строились зависимости $S_{m}(t)$ (вставки на рис. 2). Принималось допущение, что аэрозольное облако имеет форму сферы, а ее миделево сечение представляет собой окружность. По формуле $D_{a}=2\left(S_{m} / \pi\right)^{0.5}$ вычислялся средний диаметр аэрозольного облака $D_{a}$. Погрешности определения $D_{a}$ не превышали $3 \%$. Далее с использованием значения $D_{a}$ определялась суммарная площадь внешней поверхности аэрозольного облака $S_{a}$. С применением аналогичного подхода можно оценивать отношения объема аэрозольного облака к объему исходной капли $\left(V_{a} / V_{d}\right)$. Во время второго этапа обработки видеокадров регистрировались диаметры исходной $\left(D_{0}\right)$ и вторичных $\left(D_{n}\right)$, т.е. образующихся после распада, капель Определялись отношения площадей свободной поверхности жидкости $S_{c} / S_{d}\left(S_{d}=S_{m}(0)\right.$ - площадь поверхности испарения до распада, $S_{c}=S_{n(1)}+S_{n(2)}+\ldots+S_{n(m)}-$ площадь поверхности испарения после распада как сумма площадей свободной поверхности вторичных ка- 


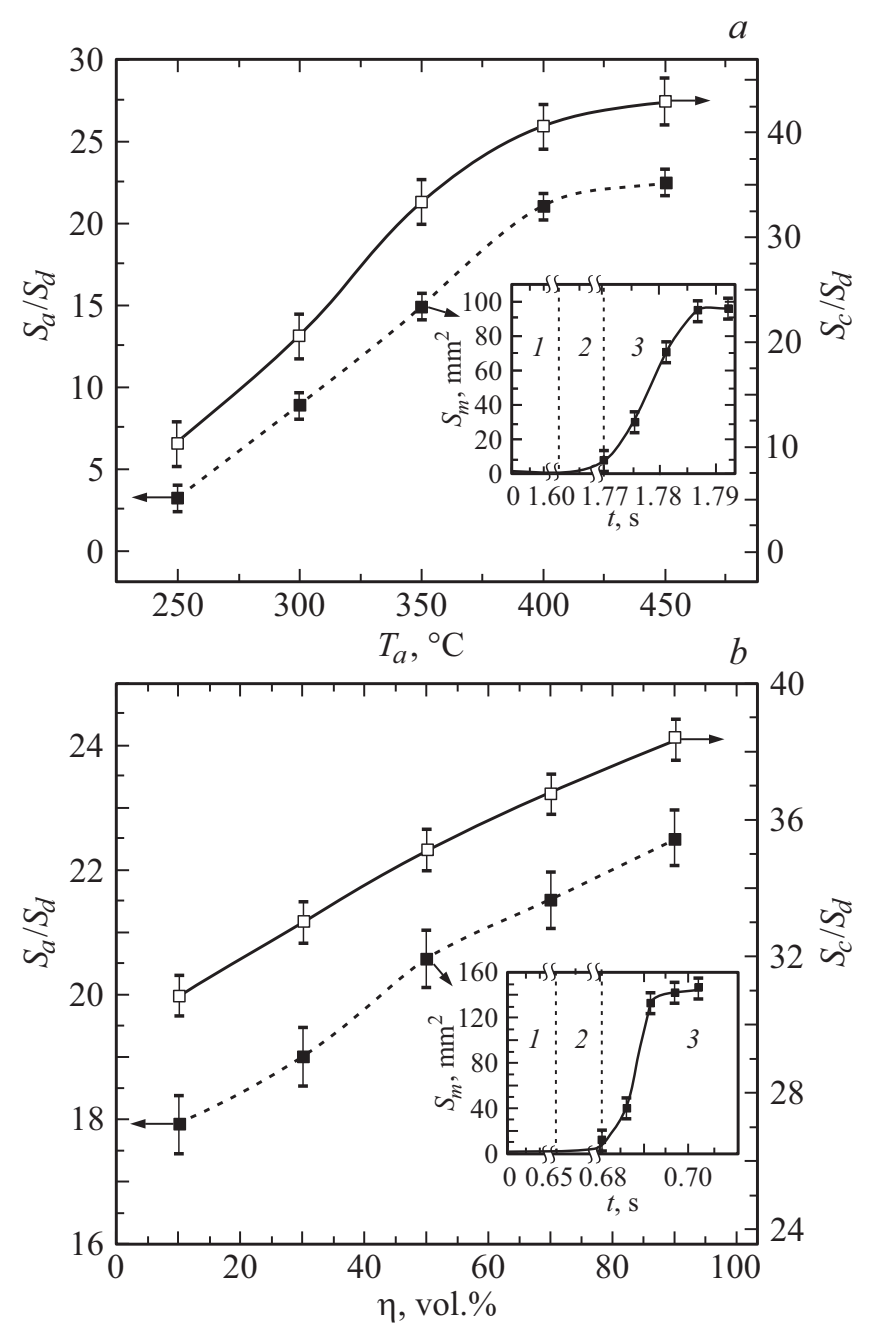

Рис. 2. Интегральные характеристики аэрозольного облака в зависимости от температуры воздушного потока (при диаметpe $D_{0} \approx 1.5 \mathrm{~mm}$ для состава $10 \%$ вода, $90 \%$ рапсовое масло) (a) и концентрации горючего компонента (при диаметре $D_{0} \approx 1.5 \mathrm{~mm}$, температуре нагрева $\left.T_{a} \approx 450^{\circ} \mathrm{C}\right)(b)$. Стадии: 1 - прогрев капли и зарождение пузырьков, 2 - рост размеров общего пузыря, 3 - рост размеров аэрозольного облака как полидисперсной совокупности жидкостных фрагментов.

пель). Погрешности вычисления размеров (диаметров) начальной и совокупности вторичных капель не превышали $3 \%$.

На рис. 2 приведены интегральные характеристики исследованных процессов микровзрывной фрагментации капель с разным содержанием воды и рапсового масла при варьировании температуры нагрева. Вне указанных диапазонов температур нагрева и концентрации компонентов регистрировались два других режима прогрева и испарения капель. В частности, при меньших температурах реализовались либо монотонное испарение жидкости, либо частичная фрагментация (принято называть „puffing“ [4-6]). В этих двух режимах невозможно обеспечить условия, при которых $S_{c} / S_{d}>1$ и $S_{a} / S_{d}>>1$. Поэтому в настоящей работе основное внимание уде- лено режиму микровзрывного распада. Приведенные на рис. 2 тренды $S_{m}(t)$ отражают типичные диапазоны изменения площади миделевого сечения исходной капли и затем аэрозольного облака на трех стадиях, основными процессами которых являются прогрев капли и зарождение пузырьков; рост размеров общего пузыря; рост размеров аэрозольного облака в виде полидисперсной совокупности фрагментов.

Рис. 2 демонстрирует условия замедления роста $S_{c} / S_{d}$ и $S_{a} / S_{d}$ при повышении $T_{a}$ и $\eta$, т.е. явно прослеживается наличие асимптот в соответствующих зависимостях. Они установлены впервые. Можно выделить несколько причин. Во-первых, чем выше концентрация жидкого горючего компонента в составе капли, тем большее количество вторичных капель должно образовываться вследствие существенно меньшего поверхностного натяжения рапсового масла по сравнению с водой. Но на рис. $2, b$ видны умеренные изменения $S_{a}$ при варьировании $\eta$. Это обусловлено тем, что при нагреве значения поверхностного натяжения масла и воды становятся сопоставимыми. Поэтому повышение доли одного или другого компонента в составе капли не оказывает масштабного влияния на количество вторичных фрагментов. Вязкость масла даже при нагреве заметно выше аналогичного параметра для воды, но этот параметр при микровзрыве не так значим в отличие от условий фрагментации, например, при соударении капель между собой или с твердой поверхностью. В этих условиях чем выше вязкость жидкости, тем крупнее образующиеся фрагменты [5,6]. Во-вторых, при повышении температуры воздуха рост количества вторичных капель вполне ожидаем (рис. 2,a) и вызван снижением поверхностного натяжения обеих жидкостей в составе капли. Интерес вызывает то, что при температуре выше $400^{\circ}$ С отношения $S_{c} / S_{d}$ и $S_{a} / S_{d}$ практически не меняются, т. е. достигли некоторых асимптотических значений. Полученный результат обусловлен тем, что при таких высоких температурах нагрева процесс парообразования настолько интенсивен, что вокруг капель образуется паровая буферная оболочка. Чем выше подводимая теплота, тем больше пара формируется. Как следствие, толщина буферного парового слоя вокруг капли становится больше. Разлет образующихся при микровзрыве мелких фрагментов жидкости тормозится этим паровым слоем. В итоге значения $S_{c} / S_{d}$ и $S_{a} / S_{d}$ меняются в пределах доверительных интервалов, соответствующих случайным погрешностям регистрации $S_{c}$ и $S_{a}$ в проведенных экспериментах при температуре выше $400^{\circ} \mathrm{C}$. В-третьих, регистрация распределений образующихся жидкостных фрагментов по размерам при разных значениях $\eta$ позволила сделать вывод о том, что с ростом температуры они различаются в пределах $10-15 \%$, т. е. в условиях высокотемпературного нагрева давление паров в каплях настолько велико, что процессы разрушения окружающей пленки жидкости с разным компонентным составом характеризуются получением фрагментов практически одинаковых размеров. При этом движение отлетающих мелких фрагментов замедляется вследствие 
сил сопротивления, вызванных давлением парогазовой смеси, и они дополнительно не фрагментируют.

Таким образом, проведенные эксперименты показали, что даже без предварительного перемешивания горючего и негорючего компонентов в составе капель жидкостей при $T>250^{\circ} \mathrm{C}$ возможно обеспечение условий интенсивной микровзрывной фрагментации, которая будет приводить к образованию аэрозольного облака с характерными размерами, в 3 раза и более превышающими начальный размер исходной капли. Отношения площадей свободной поверхности жидкости и внешнего контура аэрозольного облака к начальной площади капли с ростом температуры нагрева достигают асимптотических значений.

\section{Финансирование работы}

Исследование выполнено при поддержке гранта Президента РФ (МД-314.2019.8).

\section{Конфликт интересов}

Авторы заявляют, что у них нет конфликта интересов.

\section{Список литературы}

[1] Zeng Y., Lee C.F.F. // Proc. Combust. Inst. 2007. V. 31. P. 2185-2193.

[2] Watanabe H., Matsushita Y., Aoki H., Miura T. // Combust. Flame. 2010. V. 157. P. 839-852.

[3] Shinjo J., Xia J., Ganippa L.C., Megaritis A. // Phys. Fluids. 2014. V. 26. P. 103302.

[4] Tarlet D., Mura E., Josset C., Bellettre J., Allouis C., Massoli P. // Int. J. Heat Mass Transf. 2014. V. 77. P. 10431054.

[5] Antonov D.V., Volkov R.S., Strizhak P.A. // Chem. Eng. Res. Des. 2018. V. 140. P. 292-307.

[6] Volkov R.S., Strizhak P.A. // Int. J. Therm. Sci. 2018. V. 127. P. 126-141.

[7] Broukal J., Hájek J. // Appl. Therm. Eng. 2011. V. 31. P. 2153-2164.

[8] Sazhin S.S., Rybdylova O., Crua C., Heikal M., Ismael M.A., Nissar Z., Aziz A.R.B.A. // Int. J. Heat Mass Transf. 2019. V. 131. P. $815-821$.

[9] Антонов Д.В., Волков Р.С., Пискунов М.В., Стрижак П.А. // Письма в ЖТФ. 2016. Т. 42. В. 5. С. 49-56.

[10] Пискунов М.В., Стрижсак П.А. // Письма в ЖТФ. 2017. T. 43. B. 12. C. 34-41. 